\title{
O PAPEL DA NATUREZA DA CIÊNCIA NA EDUCAÇÃO PARA A CIDADANIA*
}

\section{The role of the Nature of Science in citizens' education}

\author{
João Praia ${ }^{1}$ \\ Daniel Gil-Pérez ${ }^{2}$ \\ Amparo Vilches ${ }^{3}$
}

Resumo: O presente trabalho tem como propósito dar uma nova contribuição para o debate que se vem desenvolvendo, já faz algum tempo, em volta do papel da natureza da ciência na educação científica e, em particular, na formação de uma cidadania para a participação na tomada de decisões.

Palavras-chave: Natureza da ciência e da tecnologia. Alfabetização científica. Imersão na cultura científica e tecnológica. Relações ciência-tecnologia-sociedade-ambiente (CTSA). Educação para cidadania.

Abstract: This paper aims to contribute to the debate on the role of the nature of science and technology in science education, paying particular attention to preparing citizens to participate in decision making.

Key words: Nature of science and technology. Scientific literacy. Immersion in a scientific and technological culture. Science-Technology-Environment-Society (STES) relationships. Education for responsible citizenship.

\footnotetext{
*Artigo concebido como contribuição para a Década da Educação para um Desenvolvimento Sustentável, instituída pelas Nações Unidas para o período 2005-2014.

${ }^{1}$ Doutor em Didáctica das Ciências; professor associado com agregação, Centro de Investigação Didáctica e Tecnologia na Formação de Formadores, Universidade de Aveiro. Aveiro, Portugal. <jpraia@ua.pt>

${ }^{2}$ Doutor em Física; professor catedrático, disciplina Didáctica de las Ciencias Experimentales, Universitat de València. Valencia, Espanha. <daniel.gil@uv.es> ; web pessoal: http://www.uv.es/gil/

${ }^{3}$ Doutora em Química; professora catedrática, disciplina Física e Química do Ensino Secundário, IES (Instituto de Educación Secundaria) Sorolla de València. Valencia, Espanha.<amparo.vilches@uv.es>; web pessoal: http://www.uv.es/Vilches/

${ }^{1}$ Centro de Investigação Didáctica e Tecnologia na Formação de Formadores (CIDTFF) Campus Universitário de Santiago 
Praia, J.; Gil-Pérez, D.; Vilches, A.

\section{Introdução}

O presente trabalho responde ao debate suscitado, nesta mesma revista, pelo artigo "Mitos da Didáctica das Ciências acerca dos motivos para incluir a Natureza da Ciência no Ensino das Ciências" (ACEVEDO et al., 2005b), trabalho que se articula com o anterior (ACEVEDO et al., 2005a), cujo título é "La Naturaleza de la ciencia y educación científica para la participación ciudadana. Una revisión crítica". Articula-se, ainda, com anteriores contribuições de outros autores (ATKIN e BLACK, 2003; FENSHAM, 2002a, 2002b; SHAMOS, 1995; ATKIN e HELMS, 1993) que classificam de mito a idéia de que a alfabetização científica pode contribuir para formar cidadãs e cidadãos com capacidade para participar na tomada fundamentada de decisões.

Iremos centrar-nos em dois problemas estreitamente relacionados e abordados neste debate em que vimos participando e que consideramos da maior importância (GIL-PÉREZ e VILCHES, 2005a, 2005b, 2004; CACHAPUZ et al., 2005):

- Formação científica para uma cidadania que permita participar em discussões tecnocientíficas.

- Importância da natureza da ciência na educação científica e, em particular, na preparação para a tomada de decisões tecnocientíficas de interesse social.

\section{Formação científica para uma cidadania que permita participar em discussões tecnocientíficas}

Existe um amplo consenso acerca da necessidade de uma alfabetização científica que permita preparar as cidadãs e os cidadãos para a tomada de decisões. Assim, na Conferência Mundial sobre a Ciência para o século XXI, sob os auspícios da UNESCO e do Conselho Internacional para a Ciência, declara-se:

Para que um país esteja em condições de atender às necessidades fundamentais da sua população, o ensino das ciências e da tecnologia é um imperativo estratégico [...] Hoje, mais do que nunca, é necessário fomentar e difundir a alfabetização científica em todas as culturas e em todos os sectores da sociedade, [...] a fim de melhorar a participação dos cidadãos na adopção de decisões relativas à aplicação de novos conhecimentos. (DECLARAÇÃO DE BUDAPESTE, 1999)

Este argumento "democrático" é, talvez, o mais amplamente utilizado por quem reclama a alfabetização científica e tecnológica como uma componente básica de uma educação para a cidadania (DeBOER, 2000; BYBEE, 1997; FOUREZ, 1997).

No entanto, como já temos vindo a assinalar noutros artigos, alguns autores têm vindo a pôr em dúvida a conveniência e inclusive a possibilidade da generalidade dos cidadãos e cidadãs adquirirem uma formação científica realmente útil para, entre outros objectivos, participar na tomada de decisões (FENSHAM, 2002a, 2002b; JENKINS, 1999; SHAMOS, 1995; ATKIN e HELMS, 1993). Trata-se de trabalhos bem documentados que pretendem "abalar aparentes evidências", como seria, na sua opinião, a necessidade de alfabetizar cienti- 
O papel da natureza da ciência na educação...

ficamente toda a população, algo que Shamos classifica de autêntico mito no seu livro The Myth Of Scientific Literacy (SHAMOS, 1995). É preciso, pois, analisar cuidadosamente os seus argumentos (GIL-PÉREZ e VILCHES, 2005a, 2004).

$\mathrm{Na}$ opinião de Fensham (2002b), pensar que uma sociedade cientificamente alfabetizada está em melhor situação para actuar racionalmente frente aos problemas sociocientíficos, constitui uma ilusão que ignora a complexidade dos conceitos científicos implicados, como sucede, por exemplo, com o problema do aquecimento global ou os relacionados com os desenvolvimentos recentes das biotecnologias. É absolutamente irrealista, sem dúvida, querer que este nível de conhecimentos possa vir a ser adquirido mesmo nas melhores escolas. Um facto clarificador a este respeito é o resultado do Project 2061, financiado pela American Association for the Advancement of Sciences (AAAS), projecto que consistiu em pedir a uma centena de eminentes cientistas de distintas disciplinas que enumerassem os conhecimentos científicos que, em sua opinião, deveriam fazer parte da escolaridade obrigatória para garantir uma adequada alfabetização científica das crianças norte-americanas. O número total de aspectos que seriam exigidos, assinala Fensham, desafia o nosso entendimento e resulta superior à soma de todos os conhecimentos actualmente ensinados aos estudantes de élite que se preparam como futuros científicos.

Argumentos como os atrás enunciados são os que levam autores como Shamos e Fensham, entre outros, a considerar a alfabetização científica como um mito irrealizável, que provocaria, além do mais, um desperdício de recursos. Devemos, pois, renunciar à ideia de uma educação científica básica para todos, susceptível de tornar possível uma participação de cidadania na tomada de decisões?

Tentaremos mostrar, pelo contrário, que a participação na tomada fundamentada de decisões precisa dos cidadãos, mais do que de um nível de conhecimentos muito elevado, da vinculação a um mínimo de conhecimentos específicos, perfeitamente acessível para uma cidadania, com planeamentos globais e considerações éticas que não exigem qualquer especialização (GIL-PÉREZ e VILCHES, 2004). E tentaremos mostrar, igualmente, que a posse de profundos conhecimentos específicos, como os que possuem os especialistas num campo determinado de saber, não garante a adoção de decisões adequadas, mas exigem enfoques que contemplem os problemas numa perspectiva mais ampla, analisando as possíveis repercussões a médio e longo prazo, tanto no campo considerado como em outros campos. E isso é algo para que os não especialistas podem contribuir, com perspectivas e interesses mais amplos, sempre que possuam um mínimo de conhecimentos científicos específicos sobre a problemática estudada, sem os quais é impossível compreender as opções em jogo e participar na tomada de decisões fundamentadas.

Consideramos útil, para tal, analisar, como exemplo paradigmático, o problema criado pelos fertilizantes químicos e pesticidas que, a partir da Segunda Guerra Mundial, produziram uma verdadeira revolução agrícola, incrementando de forma notável a produção. Recordemos que a utilização de produtos de síntese para combater os insectos, pragas, parasitas e fungos aumentou a produtividade num período em que um notável crescimento da população mundial o exigia. E recordamos igualmente que, alguns anos depois, a Comissão Mundial do Meio Ambiente e do Desenvolvimento (1988) advertia que o seu excesso constituía uma ameaça para a saúde humana, provocando desde malformações congénitas até ao cancro, sendo, por sua vez, autênticos venenos para peixes, mamíferos e pássaros. Assim, as referidas 
substâncias que se acumulavam nos tecidos dos seres vivos chegaram a ser denominadas, conjuntamente com outras igualmente tóxicas, "Contaminantes Orgânicos Persistentes" (COP).

Este envenenamento do planeta pelos produtos químicos de síntese, e em particular pelo DDT, já havia sido denunciado, em finais dos anos 1950, por Carson (1980) no seu livro Primavera Silenciosa (título que faz referência ao desaparecimento dos pássaros), em que refere abundantes e contrastadas provas dos efeitos nocivos do DDT... o que não impediu de ser violentamente criticada e de sofrer uma acusação muito dura por parte da indústria química, dos políticos e numerosos cientistas, que negaram o valor das suas provas e a acusaram de estar contra um progresso que permitia dar de comer a uma população crescente e salvar, assim, muitas vidas humanas. Contudo, apenas dez anos mais tarde, se reconheceu que o DDT era realmente um perigoso veneno e se proibiu a sua utilização no mundo rico, ainda que, desgraçadamente, se tenha continuado a utilizar nos países em desenvolvimento.

O que nos interessa destacar aqui é que a batalha contra o DDT foi desenvolvida por cientistas como Carson (1980) em conjunto com grupos de cidadãos que foram sensíveis às suas chamadas de atenção e argumentos. De fato, Carson (1980) é hoje recordada como "mãe do movimento ecologista", pela enorme influência que teve o seu livro no aparecimento de grupos activistas que reivindicavam a necessidade da protecção do meio ambiente, assim como estando nas origens do denominado movimento CTS. Sem a acção destes grupos de cidadãos e cidadãs com capacidade para compreender os argumentos de Carson, a proibição do DDT teria acontecido muito mais tarde, com efeitos ainda mais devastadores. Convém chamar a atenção sobre a influência destes "activistas ilustrados" e da sua decisiva participação na tomada de decisões, ao fazerem seus os argumentos de Carson (1980) e exigirem rigorosos controles dos efeitos do DDT, que acabaram por convencer a comunidade científica e, posteriormente, os legisladores, obrigando à sua proibição. E convém assinalar, também, que muitos cientistas, com um nível de conhecimentos, sem dúvida alguma, superior aos desses cidadãos, não souberam ou não quiseram ver, inicialmente, os perigos associados ao uso de pesticidas.

Podemos mencionar muitos outros exemplos similares, como os relacionados com a construção de centrais nucleares e o armazenamento de resíduos radioactivos; o uso dos "aerosóis" (compostos clorofluorcarbonetados), destruidores da camada de ozono; o incremento do efeito de estufa, devido fundamentalmente à crescente emissão de $\mathrm{CO}_{2}$, que ameaça com uma mudança climática global de conseqüências devastadoras (GORE, 2007); os alimentos manipulados geneticamente etc etc.

Devemos insistir em que esta participação de cidadania na tomada de decisões, que se traduz, em geral, em evitar a aplicação apressada de inovações de que se desconhecem as conseqüências a médio e longo prazo, não supõe nenhum entrave à investigação, nem à introdução de inovações, desde que existam razoáveis garantias de segurança. De facto, a opinião pública não se opõe, por exemplo, à investigação com células-mãe embrionárias. Pelo contrário, vem apoiando a maioria da comunidade científica que reclama que se levante a proibição introduzida em alguns países devido à pressão de grupos ideológicos fundamentalistas.

Em síntese, a participação, para a cidadania, na tomada de decisões é, hoje, um facto positivo, uma garantia de aplicação do principio da precaução, que se apoia em uma crescente sensibilidade social frente às implicações do desenvolvimento técnico-científico que podem comportar riscos para as pessoas ou para o meio ambiente (NOVO, 2006; VILCHES e GILPÉREZ, 2003). A referida participação, temos de insistir, reclama um mínimo de formação científica que torne possível a compreensão dos problemas e das opções - que se podem e se 
devem expressar numa linguagem acessível - para não se ver recusada com o argumento de que problemas como a mudança climática ou a manipulação genética são de uma grande complexidade. Naturalmente, são necessários estudos científicos rigorosos, mas tão pouco eles, por si sós, bastam para adoptar decisões adequadas, dado que, por vezes, a dificuldade não está na falta de conhecimentos, mas na ausência de um planeamento global que avalie os riscos e contemple as possíveis conseqüências a médio e a longo prazo. Muito ilustrativo a este respeito pode ser a ênfase dada às catástrofes anunciadas, como a provocada pelo afundamento do Prestige e outros petroleiros, que se querem apresentar como "acidentes" (VILCHES e GIL-PÉREZ, 2003).

O que acabamos de referir constitui um argumento decisivo a favor de uma alfabetização científica dos cidadãos, cuja necessidade aparece cada vez com mais clareza perante a situação de autêntica "emergência planetária" (BYBEE, 1991) que estamos vivendo. Assim, na Conferência das Nações Unidas sobre Meio Ambiente e Desenvolvimento, celebrada no Rio de Janeiro em 1992 e conhecida como Primeira Cimeira da Terra, se reclamou uma decidida acção dos educadores para que cidadãos e cidadãs adquiram uma correcta percepção de qual é essa situação e possam participar na tomada de decisões fundamentadas (GIL-PÉREZ et al., 2003; EDWARDS et al., 2001). Uma situação cuja gravidade levou as Nações Unidas a instituir uma Década da Educação por um Futuro Sustentável para o período 2005-2014 (GIL-PÉREZ et al., 2006, <http://www.oei.es/decada/>). Como assinalam Hicks e Holden (1995), se os estudantes têm de chegar a ser cidadãos e cidadãs responsáveis, é preciso que lhes proporcionemos ocasiões para analisar os problemas globais que caracterizam essa situação de emergência planetária e considerar possíveis soluções para eles.

Sendo assim, a alfabetização científica não só não constitui um "mito irrealizável" (SHAMOS, 1995), antes se impõe como uma dimensão essencial de uma cultura de cidadania, para fazer frente aos graves problemas com que há-de enfrentar-se a humanidade hoje e no futuro. Cabe-nos assinalar, por outro lado, que a reivindicação desta dimensão não é fruto de "uma idéia preconcebida" aceite acriticamente, como afirma Fensham (2002a, 2002b). Muito pelo contrário, o prejuízo tem sido e continua a ser que "a maioria da população é incapaz de aceder aos conhecimentos científicos, que exigem um alto nível cognitivo", o que implica, obviamente, reservá-los a uma pequena elite. A recusa da alfabetização científica lembra, assim, a sistemática resistência histórica dos privilegiados a um alargamento da cultura e à generalização da educação. (GIL-PÉREZ e VILCHES, 2001). E a sua reivindicação faz parte da batalha das forças progressistas para vencer as referidas resistências, que constituem o verdadeiro preconceito acrítico.

Mas esta aposta numa educação científica orientada para que as pessoas possam ser intervenientes e participantes activos na sociedade (ACEVEDO et al., 2005b), quer dizer, orientada para a formação de uma cidadania, em vez de uma preparação para futuros cientistas, gera resistências em numerosos professores, que argumentam, legitimamente, que a sociedade necessita de cientistas e tecnólogos que têm de formar-se e ser adequadamente seleccionados desde os primeiros tempos (VILCHES, SOLBES e GIL-PÉREZ, 2004). É preciso denunciar, com clareza, a falácia desta contraposição entre ambas as orientações curriculares, e os argumentos que supostamente lhe dão aval.

É necessário insistir, efectivamente, em que uma educação científica como a praticada até aqui, tanto no ensino secundário como na própria universidade, centrada quase exclusivamente nos aspectos conceptuais, é igualmente criticável como preparação para futuros cien- 
tistas, e que dificulta, paradoxalmente, a aprendizagem conceptual. Com efeito, a investigação em didáctica das ciências tem vindo a mostrar que os estudantes desenvolvem melhor a sua compreensão conceptual e aprendem mais acerca da natureza da ciência quando participam em investigações científicas, desde que haja suficientes oportunidades e apoio para a reflexão (HODSON, 1992). Por outras palavras, o que a investigação está a mostrar é que a compreensão significativa dos conceitos exige superar o reducionismo conceptual e planear o ensino das ciências como uma actividade, próxima à investigação científica, que integre os aspectos conceptuais, procedimentais e axiológicos (VILCHES, SOLBES e GIL-PÉREZ, 2004). Isso remete-nos para a discussão acerca do papel da natureza da ciência - NdC - na educação científica e, em particular, na tomada de decisões tecnocientíficas com interesse social, que constitui o segundo dos problemas objecto de debate que nos interessa abordar.

\section{Importância da natureza da ciência na educação científica}

Como Acevedo et al. (2005a, 2005b) nos recordam, é comum os currículos de ciências estarem demasiado centrados nos conteúdos conceptuais e não processuais, tendo como referência a lógica interna da própria ciência e, assim, esquecem a formação que exige a construção científica. Tal justifica-se pela complexidade da $\mathrm{NdC}$ e pelo facto de que os próprios filósofos e sociólogos da ciência terem, por vezes, muitas divergências sobre os princípios básicos desta. Por outro lado, fazem-se eco de trabalhos que apresentam resultados explicitamente contrários à influência da $\mathrm{NdC}$ em decisões de natureza sociocientíficas (BELL e LEDERMAN, 2003). O principal resultado obtido, que os autores referem, diz respeito aos diversos pontos de vista sobre a $\mathrm{NdC}$, já que esta não era, nomeadamente, um factor crucial para a tomada de decisões.

Resultados como os mencionados levam Acevedo et al. (2005a) a concluir que A Didáctica das Ciências passa mitos e crenças que não estão suficientemente suportados pela investigação educacional, que, aliás, ela própria diz produzir. E nas reflexões finais do referido artigo (ACEVEDO et al., 2005b), afirmam que a Didáctica das Ciências considera, hoje, que é importante ensinar algo de $\mathrm{NdC}$ nas aulas de ciências, sendo essa uma das diferentes formas de melhorar a educação para a cidadania, já que há uma forte tentativa, nas condições concretas do sociedade em que vivemos, para a participação interveniente nas decisões tecnocientíficas. Não obstante, os resultados das investigações citadas neste estudo deveriam fazer-nos (re)considerar a influência de outros factores pelo menos tão importantes como a $\mathrm{NdC}$, se não mais, o que torna mais complexa a temática colocada. Além disso, se se crê necessária a sua inclusão na educação científica, ficaria, ainda, por resolver o problema de qual deveria ser a $\mathrm{NdC}$ que devemos ensinar.

Como já assinalámos neste debate (GIL-PÉREZ e VILCHES, 2005b), consideramos que resultados como os de Bell e Lederman (2003) não questionam o papel da NdC na educação científica - e, em particular, na tomada de decisões - e que, pelo contrário, uma adequada alfabetização exige, precisamente, a imersão dos estudantes numa cultura científica (BYBEE, 1997). Uma imersão que deve ir mais além da aquisição de "pontos de vista sobre a NdC". Tentaremos, de seguida, fundamentar esta tese.

Convém recordar que numerosos e concordantes análises sobre o ensino das ciências têm mostrado que o ensino transmite visões da ciência que se afastam notoriamente da forma 
O papel da natureza da ciência na educação...

como se constróiem e evoluem os conhecimentos científicos (FERNÁNDEZ et al., 2002; GIL-PÉREZ et al., 2001; McCOMAS, 1998). Visões empobrecidas e distorcidas que geram o desinteresse, quando não mesmo o abandono, de muitos estudantes, e se convertem num obstáculo para a aprendizagem. Até que se compreendeu, como afirmam Guilbert e Meloche (1993), que a melhoria da educação científica exige, como requisito inquestionável, modificar a imagem da $\mathrm{NdC}$ que os professores têm e transmitem.

Tal está relacionado com o facto de que o ensino científico - incluindo o universitário - está reduzido basicamente à apresentação de conhecimentos já elaborado, sem dar ocasião aos estudantes de tomarem contacto com as actividades características da actividade científica (GIL-PÉREZ et al., 1999). Deste modo, as concepções dos estudantes - incluindo a dos futuros docentes - não chegam a diferir do que se usa denominar-se uma imagem "folk", "naif" ou "popular" da ciência, socialmente aceite, associada a um suposto "Método Científico", com maiúsculas, perfeitamente definido (FERNÁNDEZ et al., 2002; GIL-PÉREZ et al., 2001).

Poder-se-ia argumentar que esta dissonância, no fundo, não tem importância, dado que não tem impedido que os docentes desempenhem a tarefa de transmissores de conhecimentos científicos. Contudo, as limitações de uma educação científica centrada na mera transmissão de conhecimentos - posta em relevo por uma abundante literatura, recolhida em boa parte nos Handbooks já aparecidos (PERALES e CAÑAL, 2000; FRASER e TOBÍN, 1998; GABEL, 1994) - têm impulsionado investigações que assinalam as concepções epistemológicas "de senso comum" como um dos principais obstáculos para movimentos de renovação no campo da educação científica.

Percebeu-se assim que, se queremos mudar o que os professores e os alunos fazem nas aulas de ciências, é preciso previamente modificar a epistemologia dos professores (BELL e PEARSON, 1992). Mas, embora possuir concepções válidas acerca da ciência não garanta que o comportamento docente seja coerente com as ditas concepções, isso constitui um requisito sine qua non. O estudo das referidas concepções tem-se convertido, por essa razão, numa poderosa linha de investigação, e tem colocado a necessidade de estabelecer o que pode entender-se como una imagem adequada, não distorcida, sobre a natureza da ciência e da actividade científica, coerente com a epistemologia actual.

Estamos conscientes das dificuldades que se colocam ao falar de uma "imagem adequada" da actividade científica, que parece sugerir a existência de um suposto método universal, de um modelo único de desenvolvimento científico. É preciso evitar qualquer interpretação deste tipo, mas tal não se consegue renunciando a falar das características da actividade científica; consegue-se com um esforço consciente para evitar simplismos e deformações claramente contrárias ao que pode entender-se, em sentido amplo, como aproximação científica ao tratamento de problemas.

Como a literatura tem mostrado, diversos estudos têm evidenciado, de forma convergente, a existência de um conjunto de distorções, estreitamente relacionadas, cuja superação pode servir de base a um consenso acerca de como orientar a imersão numa cultura científica, ou melhor dito, numa cultura científica e tecnológica, pois as visões empobrecidas, distorcidas, afectam tanto a natureza da ciência como a da tecnologia, e devem ser abordadas conjuntamente (CACHAPUZ et al., 2005; GIL-PÉREZ et al., 2005; GIL-PÉREZ e VILCHES, 2003; FERNÁNDEZ et al., 2002; GIL-PÉREZ, 1993).

No entanto, como têm mostrado também estas mesmas investigações, um trabalho 
colectivo de reflexão crítica permite um distanciamento destas visões deformadas e a aquisição de uma visão mais adequada da actividade científica e tecnológica, a qual expressa o consenso básico de diversos epistemólogos (LAUDAN, 1984; LAKATOS, 1982; TOULMIN, 1977; BUNGE, 1976; FEYERABEND, 1975; KUHN, 1971; POPPER, 1962 etc), à margem das suas discrepâncias e debates pontuais. Podemos resumir este consenso nos seguintes pontos:

1. Em primeiro lugar, podemos referir a recusa da própria ideia de "Método Científico", com maiúsculas, como um conjunto de regras perfeitamente definidas a aplicar mecanicamente e independentes do domínio investigado. Diz Bunge (1976): “A expressão (Método Cientifico) é traiçoeira, pois pode levar a pensar que significa um conjunto de receitas exaustivas e infalíveis..."

2. Em segundo lugar, há que ter em atenção a recusa do que Piaget (1970, p. 83) denomina "o mito da origem sensorial dos conhecimentos científicos", isto é, a recusa de um empirismo que concebe os conhecimentos como resultado da inferência indutiva a partir de "dados puros". Esses dados não significam nada em si mesmos, mas devem ser interpretados de acordo com um sistema teórico. Insiste-se, por isso, que toda a investigação e busca de dados devem vir acompanhados por paradigmas teóricos, isto é, por perspectivas coerentes, articuladas, que orientem a referida investigação.

É preciso insistir na importância dos paradigmas conceptuais, das teorias, como princípio e fim do trabalho científico (BUNGE, 1976), num processo complexo que inclui eventuais rupturas, mudanças revolucionárias do paradigma em uso num determinado domínio e aparecimento de novos paradigmas teóricos. É preciso igualmente insistir na idia de que os problemas científicos constituem', inicialmente, "situações problemáticas" confusas: o problema não surge bem definido, sendo necessário formulá-lo de maneira precisa, modelizando a situação, fazendo determinadas opções com vista a simplificá-lo mais ou menos, para poder ser abordado, clarificando o seu objectivo etc. Tudo isto deve partir do corpus de conhecimento existente no campo específico em que se realiza a investigação.

3. Em terceiro lugar, é necessário evidenciar o papel do pensamento divergente na investigação, que se concretiza em aspectos fundamentais e erradamente afastados nas abordagens empiristas, como são a criação de hipóteses e de modelos ou o próprio desenho de experiências. Não se raciocina, pois, em termos de certezas, mais ou menos baseadas em evidências, mas em termos de hipóteses, que se apoiam, é certo, nos conhecimentos adquiridos, mas que são consideradas como simples tentativas de resposta que deverão ser postas à prova o mais rigorosamente possível. Segundo Hempel (1976), não se atinge o conhecimento científico aplicando um procedimento indutivo de inferência a dados recolhidos anteriormente, mas mediante o chamado método das hipóteses à procura de respostas a um problema em estudo, e submetendo, de imediato, estas hipóteses à contraprova empírica. São, então, as hipóteses que orientam a busca de dados. Hipóteses essas que, por seu lado, nos remetem para o paradigma conceptual de partida, pondo de novo em evidência o erro das abordagens empiristas.

4. Outra característica fundamental é a busca de coerência global (CHALMERS, 2004). O facto de se trabalhar em termos de hipóteses introduz exigências suplementares de rigor: é preciso duvidar sistematicamente dos resultados obtidos e de todo o processo seguido para os obter, o que conduz a revisões contínuas, a tentar obter esses resultados por caminhos diversos e, particularmente, a mostrar a sua coerência com os resultados obtidos noutras situações. É necessário chamar aqui a atenção para as interpretações simplistas dos resultados das experiências e para um possível "reducionismo experimentalista": não basta um tratamento expe- 
rimental para recusar ou verificar uma hipótese; trata-se, sobretudo, da existência, ou não, de coerência global com a referência de um corpus de conhecimentos.

Assim, uma das finalidades mais importantes da ciência apoia-se na vinculação de domínios aparentemente desconexos. Num mundo em que o mais evidente é a existência de uma grande diversidade de materiais e de seres, submetidos a constantes mudanças, a ciência procura estabelecer leis e teorias gerais que sejam aplicáveis ao estudo do maior número possível de fenómenos. A teoria atómico-molecular da matéria, a síntese electro-magnética, os princípios de conservação e de transformação, os esforços que se realizaram e continuam a realizar-se para unificar os diferentes tipos de interacção existentes na natureza etc., são bons exemplos dessa busca de coerência e globalidade, embora se deva realizar partindo de problemas e de situações particulares inicialmente muito concretas. $\mathrm{O}$ desenvolvimento científico contém, assim, a finalidade de estabelecer generalizações aplicáveis à natureza. Essa exigência de aplicabilidade, de funcionamento correcto para descrever fenómenos, realizar previsões, abordar e planear novos problemas etc, é precisamente o que dá validade (não dá certeza ou carácter de verdade indiscutível) aos conceitos, leis e teorias que se elaboram.

5. Por último, é preciso compreender o carácter social do desenvolvimento científico, evidente não só no facto de que o ponto de partida do paradigma teórico vigente é a cristalização dos contributos de gerações de investigadores, mas também no facto de que a investigação responde cada vez mais a estruturas institucionalizadas (MATTHEWS, 1994, 1991; KUHN, 1971; BERNAL, 1967) onde o trabalho dos indivíduos é orientado por linhas de investigação estabelecidas, pelo trabalho da equipa a que pertencem, não fazendo praticamente sentido a idéia de investigação completamente autónoma. Além disso, o trabalho dos homens e mulheres de ciências - como qualquer outra actividade humana - não acontece à margem da sociedade em que vivem, e é influenciado, logicamente, pelos problemas e circunstâncias do momento histórico, da mesma forma que a sua acção tem uma clara influência sobre o meio físico e social em que se insere. Assinalar isto pode parecer supérfluo; no entanto, a idéia de que fazer ciência é pouco menos do que uma tarefa de "génios solitários" que se fecham numa torre de marfim, desligados da realidade, constitui uma imagem-tipo muito disseminada e que a escola, lamentavelmente, não ajuda a superar, dado que se limita à transmissão de conteúdos conceptuais e, em suma, de treino de alguma destreza, mas deixando de lado os aspectos históricos, sociais, éticos, do meio ambiente... que marcam o desenvolvimento científico.

Desenha-se, assim, uma imagem imprecisa, nebulosa, da metodologia científica longe de qualquer idéia de algoritmo com que freqüentemente se apresenta - na qual nada garante que se chegará a um bom resultado, mas que representa, sem dúvida, a melhor forma de orientar o tratamento de um problema científico (como atestam os impressionantes edifícios teóricos construídos).

Podemos dizer, em síntese, que a essência da actividade científica - deixando de lado toda a idéia de "método" - encontra-se na mudança de um pensamento e de uma acção baseados nas "evidências" do senso comum, para um pensamento em termos de hipóteses, ao mesmo tempo mais criativo (é necessário ir mais longe do que o que parece evidente e imaginar novas possibilidades) e mais rigoroso (é necessário fundamentar as hipóteses e depois submetê-las cuidadosamente a prova, duvidar dos resultados e procurar a coerência global).

Por outro lado, é preciso ter presente que o trabalho científico exige tratamentos analíticos, simplificativos, artificiais. Mas não supõe, como às vezes se critica, incorrer neces- 
sariamente em visões parcelares e simplistas: na medida em que se trata de análises e de simplificações conscientes, tem-se presente a necessidade de elaborar sínteses e estudos de complexidade crescente.

Podemos resumir afirmando que a idéia de "método científico" perdeu hoje as maiúsculas, isto é, a sua suposta natureza de caminho rigoroso - conjunto de operações ordenadas - e infalível, assim como a sua suposta neutralidade. Isto não significa, claro está, negar aquilo que de específico a ciência moderna trouxe ao tratamento dos problemas: a ruptura com um pensamento baseado em estudos pontuais, nas "evidências" do senso comum e em dogmas, introduzindo um pensamento apoiado num sistemático questionamento do óbvio e numa exigência de coerência global que se mostrou muito fecunda.

Cabe aqui perguntarmo-nos se todo este esforço de clarificação teórica vale realmente a pena. Como Guilbert e Meloche (1993), assinalam, a compreensão, pelos docentes, dos modos de construção do conhecimento científico (...) não é somente um debate teórico, mas um debate também fortemente prático. Trata-se, pois, de compreender a importância prática, para o ensino e para a aprendizagem, do que os estudos e investigações realizadas mostraram, e poder tirar um maior proveito desses mesmos estudos, levando-nos a perceber que é isso que queremos potenciar no trabalho dos nossos alunos e alunas.

\section{Importância da superação das visões distorcidas da natureza da ciência na educação científica}

O trabalho de clarificação realizado mostra a necessidade de nos afastarmos dos habituais reducionismos e de incluir aspectos que são, não só essenciais para uma investigação científica, mas que se tornam também imprescindíveis para favorecer uma aprendizagem realmente significativa, não memorizada, das ciências. Como já mostraram diversas linhas de investigação, uma aprendizagem significativa e duradoura é facilitada pela participação dos estudantes na construção de conhecimentos científicos e pela sua familiarização com as estratégias e as atitudes científicas (CACHAPUZ et al., 2005; FERNÁNDEZ et al., 2005; GILPÉREZ et al., 1999; HODSON, 1992).

Propomos, em síntese, planear a aprendizagem como um trabalho de investigação e de inovação por meio do tratamento de situações problemáticas relevantes para a construção de conhecimentos científicos e a conquista de inovações tecnológicas susceptíveis de satisfazer determinadas necessidades (STINNER, 1995). Isso deve ser considerado como uma actividade aberta e criativa, devidamente orientada pelo professor, que se inspira no trabalho de cientistas e de tecnólogos, e que deveria incluir toda uma série de aspectos como os que passamos a enumerar (GIL-PÉREZ e VILCHES, 2004; GIL-PÉREZ et al., 1999):

- A discussão do possível interesse e da relevância das situações propostas, que dê sentido ao seu estudo e evite que os alunos se vejam submergidos no tratamento de uma situação sem terem sequer podido formar uma primeira idéia motivadora ou percebido a necessária tomada de decisões, por parte da sociedade e da comunidade científica, acerca da conveniência ou da inconveniência do referido trabalho, tendo em conta a sua possível contribuição para a compreensão e transformação do mundo, suas repercussões sociais e do meio ambiente etc. 
O papel da natureza da ciência na educação...

- O estudo qualitativo, significativo, das situações problemáticas abordadas, que ajude a compreender e a precisar tais situações à luz dos conhecimentos disponíveis, dos objectivos perseguidos... e a formular perguntas operativas sobre o que se procura, o que supõe uma oportunidade para os estudantes começarem a explicitar funcionalmente as suas 'concepções alternativas'.

- A invenção de conceitos e a formulação de hipóteses fundamentadas nos conhecimentos disponíveis, capazes de focalizar e de orientar o tratamento das situações, enquanto permitem aos estudantes utilizar as suas concepções alternativas para fazer previsões susceptíveis de ser submetidas à prova.

- A definição e implementação de estratégias de resolução, incluindo, se for caso disso, o plano e a realização de experiências para submeter à prova as hipóteses à luz do corpo de conhecimentos de que se dispõe, o que exige um trabalho de natureza tecnológica para a resolução dos problemas práticos que possam surgir, como, por exemplo, a redução das margens de erro nas medições. Chamamos particularmente a atenção sobre o interesse destes planos e da realização de experiências que exigem e ajudem a desenvolver uma multiplicidade de capacidades e de conhecimentos. Acaba-se, assim, com as aprendizagens erradamente designadas de 'teóricas' (na realidade, simplesmente livrescas) e contribui-se para mostrar a estreita relação ciência-tecnologia.

- A análise e comunicação dos resultados, comparando-os com os obtidos por outros grupos de estudantes e aproximando-se da evolução conceptual e metodológica experimentada historicamente pela comunidade científica. Isso pode converter-se em ocasião de conflito cognitivo entre distintas concepções, tomadas todas elas como hipóteses, e favorecer a 'auto-regulação' dos estudantes, obrigando a conceber novas conjecturas ou novas soluções técnicas e a replanear a investigação. É preciso chamar a atenção sobre a importância da comunicação como substracto da dimensão colectiva do trabalho científico e tecnológico. Isso supõe que os estudantes se familiarizem com a leitura e construção de memórias científicas e trabalhos de divulgação.

- As sínteses e a possibilidade de outras perspectivas: articulação dos conhecimentos construídos com outros já conhecidos, considerando a sua contribuição para a construção de corpos coerentes de conhecimentos que se vão ampliando e modificando, com especial atenção para o estabelecimento de pontes entre distintos domínios científicos, porque representam pontos altos de desenvolvimento científico e, por vezes, autênticas revoluções científicas; construção e aperfeiçoamento dos produtos tecnológicos que se procuravam ou que são concebidos como resultado das investigações realizadas, o que contribui para acabar com tratamentos excessivamente escolares e reforçar, então, o interesse pela tarefa; apresentação de novos problemas... Tudo isso se converte em oportunidades de uso repetido dos novos conhecimentos numa variedade de situações, contribuindo para o seu aprofundamento e realçando, em particular, as relações Ciência, Tecnologia, Sociedade e Ambiente (CTSA), que marcam o desenvolvimento científico, com destaque para as repercussões de todo o tipo de conhecimentos científicos e tecnológicos (desde a contribuição da ciência e da técnica para o desenvolvimento da humanidade até aos graves problemas que hipotecam o seu futuro), permitindo a preparação para a cidadania na tomada de decisões, da forma como já foi apresentada no capítulo anterior.

Devemos, ainda, insistir na necessidade de dirigir todo este tratamento para mostrar o carácter de corpo coerente que tem toda a ciência, valorizando, para isso, as actividades de 
síntese (esquemas, memórias, revisões, mapas conceptuais...) e a elaboração de produtos, capazes de acabar com planos excessivamente escolares, de reforçar o interesse pela tarefa e de mostrar a estreita ligação ciência-tecnologia.

Contudo, é conveniente realçar que as orientações precedentes não constituem um algoritmo que pretenda orientar passo a passo a actividade dos alunos; são indicações genéricas que chamam a atenção sobre os aspectos essenciais a ter em conta na construção de conhecimentos científicos que, freqüentemente, não são suficientemente tidos em conta na educação científica. E estamos a referir-nos tanto aos aspectos metodológicos como aos aspectos axiológicos: relações CTSA, tomada de decisões, comunicação de resultados... A aprendizagem das ciências é encarada, assim, como um processo de investigação orientada que permite aos alunos participar colectivamente na aventura de enfrentar problemas relevantes e (re)construir os conhecimentos científicos (HODSON, 1992).

Esta orientação supõe querer dizer que devemos prestar mais atenção aos aspectos culturais, sociais, morais e emotivos [...] e aos aspectos atitudinais e axiológicos do que é habitual na educação científica (ACEVEDO et al., 2005a, 2005b). Tal não deve entender-se como a incorporação de outros factores, distintos da $\mathrm{NdC}$, mas como a superação de uma distorção da referida $\mathrm{NdC}$, que apresenta o trabalho científico como uma actividade descontextualizada, alheia a interesses e conflitos.

Pretende-se, assim, fomentar a alfabetização científica e tecnológica dos cidadãos por intermédio de uma certa imersão na cultura científica e tecnológica, fundamental para a formação de cidadãos e cidadãs críticos que, no futuro, participarão na tomada de decisões... e igualmente fundamental para que os futuros homens e mulheres de ciência consigam uma melhor apropriação dos conbecimentos elaborados pela comunidade científica.

O enriquecimento do currículo de ensino das ciências que reflicta as propostas precedentes, reiteradamente postas em prática com estudantes e com professores em formação (GIL-PÉREZ et al., 2005), é um bom exemplo da incidência positiva que pode ter a clarificação da $\mathrm{NdC}$ (e a tecnologia), se essa clarificação não se limitar a uma mera exposição verbal de determinadas características, mas abrir caminho a uma autêntica imersão numa cultura científica e tecnológica.

Por solicitação dos autores do artigo, nas referências com vários autores, todos aparecem citados.

\section{Referências}

ACEVEDO, J. A.; VÁZQUEZ, A.; MARTÍN, M.; OLIVA, J. M.; ACEVEDO, P.; PAIXAO, M. F.; MANASSERO, M. A. La naturaleza de la ciencia y la educación científica para la participación ciudadana: una revisión crítica. Revista Eureka sobre Enseñanza y divulgación de las Ciencias, Cádiz (Espanha), v. 2, n. 2, p. 121-140, 2005a.

$$
\text { ; _ PAIXAO, M. F.; ACEVEDO, P.; OLIVA, J. M.; MANASSERO, M. }
$$

Mitos da didática das ciências acerca dos motivos para incluir a natureza da ciência no ensino das ciências. Ciência \& Educação, Bauru, v. 11, n. 1, p. 1-15, 2005b. 
O papel da natureza da ciência na educação...

ATKIN, J. M.; BLACK, P. Inside science education reform. Buckingham: Open University Press and New York/Teachers College Press, 2003.

; HELMS, J. Getting serious about priorities in science education. Studies in Science Education, Leeds (England), v. 21, p. 1-20, 1993.

BELL, B. F.; LEDERMAN, N. Understandings of the nature of science and decision making on science and technology based issues. Science Education, Hoboken New Jersey, v. 87, n. 3 , p. 352-377, 2003.

; PEARSON, J. Better learning. International Journal of Science Education, London, v. 4, n. 3, p. 349-361, 1992.

BERNAL, J. D. Historia social de la ciencia. Barcelona: Península, 1967.

BUNGE, M. Filosofía de la Física. Barcelona: Ariel, 1976.

BYBEE, R. Towards an understanding of scientific. In: GRAEBER, W.; BOLTE, C. (Eds.). Scientific literacy. Kiel: IPN, 1997. p. 37-68.

Planet earth in crisis: how should science educators respond? The American

Biology Teacher, Reston, Virginia (USA), v. 53, n. 3, p. 146-153, 1991.

CACHAPUZ, A.; GIL-PÉREZ, D.; PESSOA, A. M.; PRAIA, J.; VILCHES, A. A

necessária renovação do ensino das Ciências. São Paulo: Cortez, 2005.

CARSON, R. Primavera silenciosa. Barcelona: Grijalbo, 1980.

CHALMERS, A. F. What's this thing called science? 3. ed. Buckingham: Open University Press, 2004.

COMISIÓN MUNDIAL DEL MEDIO AMBIENTE Y DEL DESARROLLO. Nuestro futuro común. Madrid: Alianza, 1988.

DeBOER, G. E. Scientific literacy: another look at its historical and contemporary meanings and its relationship to science education reform. Journal of Research in Science Teaching, Hoboken, New Jersey (USA), v. 37, n. 6, p. 582-601, 2000.

DECLARAÇÃO DE BUDAPESTE. Marco general de acción de la declaración de Budapest, 1999. Disponível em: <http://www.unesco.org/science/wcs/esp/ declaracion_s.htm>. Acesso em: 11 jul. 2007.

EDWARDS, M.; GIL-PÉREZ, D.; VILCHES, A.; PRAIA, J.; VALDÉS, P.; VITAL, M. L.; CAÑAL, P.; DEL CARMEN, L.; RUEDA, C.; TRICÁRICO, H. Una propuesta para la transformación de las percepciones docentes acerca de la situación del mundo: primeiros resultados. Didáctica de las Ciencias Experimentales y Sociales, Valencia, v. 15, p. 3767, 2001.

FENSHAM, P. J. Time to change drivers for scientific literacy. Canadian Journal of Science, Mathematics and Technology Education, Toronto, v. 2, n. 1, p. 9-24, 2002 a. 
Praia, J.; Gil-Pérez, D.; Vilches, A.

. De nouveaux guides pour l'alphabétisation scientifique. Canadian Journal of

Science, Mathematics and Technology Education, Toronto, v. 2, n. 2, p. 133-149, 2002b.

FERNÁNDEZ, I.; GIL-PÉREZ, D.; VALDÉS, P.; VILCHES, A. ¿Qué visiones de la ciencia y la actividad científica tenemos y transmitimos? In: GIL-PÉREZ, D.; MACEDO, B.; MARTÍNEZ TORREGROSA, J.; SIFREDO, C.; VALDÉS, P.; VILCHES, A. (Eds.).

¿Cómo promover el interés por la cultura científica? Una propuesta didáctica fundamentada para la educación científica de jóvenes de 15 a 18 años. Santiago de Chile: OREALC/UNESCO, 2005. p. 29-62.

.; ___ _ CARRASCOSA, J.; CACHAPUZ, J.; PRAIA, J. Visiones deformadas de la ciencia transmitidas por la enseñanza. Enseñanza de las Ciencias, Barcelona, v. 20, n. 3, p. $477-488,2002$.

FEYERABEND, P. Against method. Londres: Verso, 1975.

FOUREZ, G. Alfabetización científica y tecnológica: acerca de las finalidades de la enseñanza de las ciencias. Buenos Aires: Colihue, 1997.

FRASER, B. J.; TOBIN, K. G. International handbook of science education. London: Kluwer Academic Publishers, 1998.

GABEL, D. L. Handbook of research on science teaching and learning. New York: McMillan, 1994.

GIL-PÉREZ, D. Contribución de la historia y la filosofía de las ciencias al desarrollo de un modelo de enseñanza/aprendizaje como investigación. Enseñanza de las Ciencias, Barcelona, v. 11, n. 2, p. 197-212, 1993.

; VILCHES, A.; TOSCANO, J. C.; MACÍAS, O. Década de la Educación para un futuro sostenible (2005-2014): un necesario punto de inflexión en la atención a la situación del planeta. Revista Iberoamericana de Educación, Madrid, v. 40, p. 125-178, 2006.

; . Contribution of science and technological education to citizens' culture. Canadian Journal of Science, Mathematics \&Technology Education, Toronto, v. 5, n. 2, p. 85-95, 2005a.

; In Inersión en la cultura científica para la toma de decisiones. ¿Necesidad

o mito? Revista Eureka sobre Enseñanza y Divulgación de las Ciencias, Cádiz, v. 2, n. 3, p. 302-329, 2005b.

; ___ ; FERNÁNDEZ, I.; CACHAPUZ, A.; PRAIA, J.; VALDÉS, P.;

SALINAS, J. Technology as 'applied science': a serious misconception that reinforces distorted and impoverished views of science. Science \& Education, Dordrecht, The Netherlands, v. 14, n. 3 -5, p. 309-320, 2005. ; L La contribución de la ciencia a la cultura ciudadana. Cultura y

Educación, Salamanca, v. 16, n. 3, p. 259-272, 2004. 
O papel da natureza da ciência na educação...

; . Technology as "applied science": a serious misconception of the nature of technology and the nature of science. In: INTERNATIONAL HISTORY, PHILOSOPHY OF SCIENCE AND SCIENCE TEACHING CONFERENCE, 7., 2003, Winnipeg. Proceedings... Winnipeg, 2003. p. 342-352.

; ___ ; EDWARDS, M.; PRAIA, J.; MARQUES, L.; OLIVEIRA, T. A proposal to enrich teachers' perception of the state of the world. First results. Environmental Education Research, London, v. 9, n. 1, p. 67-90, 2003.

; __ Una alfabetización científica para el siglo XXI. Obstáculos y propuestas de actuación. Investigación en la Escuela, Sevilla, v. 4, n. 3, p. 27-37, 2001.

; FERNÁNDEZ, I.; CARRASCOSA, J.; CACHAPUZ, A.; PRAIA, J. Para uma imagem não deformada do trabalho científico. Ciência \& Educação, Bauru, v. 7, n. 2, p. 125-153, 2001.

; CARRASCOSA, J.; DUMAS-CARRÉ, A.; FURIÓ, C.; GALLEGO, N.; GENÉ, A.; GONZÁLEZ, E.; GUISASOLA, J.; MARTINEZ, J.; PESSOA, A.; SALINAS, J.; TRICÁRICO, H.; VALDÉS, P. ¿Puede hablarse de consenso constructivista en la educación científica? Enseñanza de las Ciencias, Barcelona, v. 17, n. 3, p. 503-512, 1999.

GORE, A. Una verdad incómoda: la crisis planetaria del calentamiento global y cómo afrontarla. Barcelona: Gedisa, 2007.

GUILBERT, L.; MELOCHE, D. L'idée de science chez des enseignants en formation: un lieu entre l'histoire des sciences et l'hétérogénéité des visions? Didaskalia, Lyon e Québec, v. 2, p. 7-30, 1993.

HEMPEL, C. G. Filosofía de la ciencia natural. Madrid: Alianza, 1976.

HICKS, D.; HOLDEN, C. Exploring the future a missing dimension in environmental education. Environmental Education Research, London, v. 1, n. 2, p. 185-193, 1995.

HODSON, D. In search of a meaningful relationship: an exploration of some issues relating to integration in science and science education. International Journal of Science Education, London, v. 14, n. 5, p. 541-566, 1992.

JENKINS, E. W. School science, citizenship and the public understanding of science. International Journal of Science Education, London, v. 21, n. 7, p. 703-710, 1999.

KUHN, T. S. La estructura de las revoluciones científicas. México: Fondo de cultura económica, 1971.

LAKATOS, I. Historia de la ciencia y sus reconstrucciones racionales. Madrid: Tecnos, 1982.

LAUDAN, L. Science and values: the aims of science and their role in the scientific debate. Berkeley: University of California Press, 1984. 
Praia, J.; Gil-Pérez, D.; Vilches, A.

MATTHEWS, M. R. Historia, filosofía y enseñanza de las ciencias: la aproximación actual, Enseñanza de las Ciencias, Barcelona, v. 12, n. 2, p. 255-277, 1994.

. Un lugar para la historia y la filosofía en la enseñanza de las ciencias.

Comunicación, Lenguaje y Educación, Madrid, n. 11-12, p. 141-155, 1991.

McCOMAS, W. F. (Ed.) The nature of science in science education: rationales and strategies. Netherlands: Kluwer Academic Publishers, 1998.

NOVO, M. El desarrollo sostenible. Su dimensión ambiental y educativa. Madrid:

Pearson/Unesco, 2006.

PERALES, F. J.; CAÑAL, P. Didáctica de las ciencias experimentales: teoría y práctica de la enseñanza de las ciencias. Alcoy: Marfil, 2000.

PIAGET, J. La epistemología genética. Barcelona: Redondo, 1970.

POPPER, K. R. La lógica de la investigación científica. Madrid: Tecnos, 1962.

SHAMOS, M. The myth of scientific literacy. New Brunswick: Rutgers University Press, 1995.

STINNER, A. Contextual settings, science stories and large context problems: towards a more humanistic science education. Science Education, Hoboken, New Jersey, v. 79, n. 5, p. 555-581, 1995.

TOULMIN, S. La comprensión humana: el uso colectivo y la evolución de los conceptos. Madrid: Alianza, 1977.

VILCHES, A.; GIL-PÉREZ, D. Construyamos un futuro sostenible: diálogos de supervivencia. Madrid: Cambridge University Press, 2003.

.; SOLBES, J.; GIL-PÉREZ, D. Alfabetización científica para todos contra ciencia para futuros científicos. Alambique, Barcelona, v. 41, p. 89-98, 2004.

Artigo recebido em dezembro de 2006 e aceito em junho de 2007. 